\title{
Elaboração e Caracterização Microbiológica de Pitaias (Hylocereus Polyrhizus) Cristalizadas
}

Anakláudia Sombra Santos (I), Maria Izamara De Jesus Norte (I), Auriana De Assis Régis (I), Hirllen Nara Bessa Rodrigues (I), Maria Gilnara Lima Bandeira (I), Monique Ellen Torres Da Silva (I), Monique De Oliveira Maia (I), Pahlevi Augusto De Souza (I), Renata Chastinet Braga (I), Rinaldo Dos Santos Araújo (I) (I) IFCE - LIMOEIRO - INSTITUTO FEDERAL DE EDUCAÇÃO, CIÊNCIA E TECNO- CEARÁ (RUA ESTEVÃO REMÍGIO, 1145 - CENTRO - LIMOEIRO DO NORTE)

\section{Resumo}

As pitaias pertencem à família Cactaceae, e ainda são pouco processadas industrialmente. Objetivou-se com esse trabalho elaborar e caracterizar amostras de pitaias cristalizadas, quanto aos aspectos microbiológicos. A produção e as análises realizadas nas frutas cristalizadas foram realizadas no Instituto Federal - Campus Limoeiro do Norte-CE. As pitaias e açúcar para o processo de cristalização foram adquiridas em comércio local. Para elaboração das pitaias cristalizadas, realizou-se a lavagem dos frutos com água corrente; sanitizou-se com solução de hipoclorito de sódio a 100ppm por cinco minutos; posteriormente retirou-se a casca dos frutos e cortou-se em formato de rodelas e em cubos. Os frutos foram branqueados (por imersão em água a $100^{\circ} \mathrm{C}$, por 1 minuto) e realizou-se a primeira saturação com açúcar, onde se utilizou uma solução de açúcar com um teor de sólidos solúveis equivalente a $60^{\circ}$ Brix. Os frutos foram imersos nessa solução fervendo por cinco minutos. Retirou-se o excesso do xarope de açúcar dos frutos, através do escoamento em peneiras de aço inox. Logo após, os mesmos foram acondicionados e armazenados sob refrigeração por 24 horas. Esse processo de imersão dos frutos em xarope de açúcar foi realizado mais duas vezes a cada 24 horas após a primeira imersão nas

\footnotetext{
Referência:

Anakláudia Sombra Santos, Maria Izamara De Jesus Norte, Auriana De Assis Régis, Hirllen Nara Bessa Rodrigues, Maria Gilnara Lima Bandeira, Monique Ellen Torres Da Silva, Monique De Oliveira Maia, Pahlevi Augusto De Souza, Renata Chastinet Braga, Rinaldo Dos Santos Araújo.Elaboração e Caracterização Microbiológica de Pitaias (Hylocereus Polyrhizus) Cristalizadas. In: Anais do 12 Congresso Latinoamericano de Microbiologia e Higiene de Alimentos - MICROAL 2014 [= Blucher Food Science Proceedings, num.1, vol.1]. São Paulo: Editora Blucher, 2014.

DOI 10.5151/foodsci-microal-134
} 
concentrações de 65 e $72^{\circ}$ Brix por cinco minutos, respectivamente. $\mathrm{O}$ excesso de solução de açúcar foi removido por escoamento e as amostras foram colocadas em estufa a $60^{\circ} \mathrm{C}$, até atingirem umidade inferior a $25 \%$. Realizou-se análises da contagem do número mais provável (NMP/g) de coliformes a $35^{\circ} \mathrm{C}$, coliformes a $45^{\circ} \mathrm{C}$ e pesquisa de Salmonella sp, segundo Siqueira 1995. De acordo com os resultados obtidos, observou-se que a contagem de coliformes a 35 e $45^{\circ} \mathrm{C}$ foi $<3 \mathrm{NMP} / \mathrm{g}$, sem formação de gás no interior dos tubos de durhan, nas três diluições. Na pesquisa de Salmonella sp. as amostras analisadas apresentaram ausência em $25 \mathrm{~g}$. Conclui-se que as pitaias cristalizadas encontram-se de acordo com os padrões microbiológicos estabelecidos pela segundo a $\mathrm{RDC} \mathrm{n}^{\circ} 12$, de 02 de janeiro de 2001, da ANVISA, para frutas cristalizadas. Portanto, o produto elaborado não apresenta risco à saúde do consumidor, indicando que durante o processamento foram adotadas as Boas práticas de Fabricação.

Palavras-Chave: Cristalização, Hylocereus polyrhizus, Qualidade Agência de Fomento: FUNCAP, CAPES, CNPq, IFCE-LIMOEIRO DO NORTE 